\title{
Breast Cancer Molecular Subtypes Defined by ER/PR and HER2 Status: Association with Clinicopathologic Parameters in Ivorian Patients
}

\author{
Ahoua B Effi' ${ }^{1}$,'guiessan A Aman ${ }^{1 *}$, Baumaney S Koui ${ }^{2}$, Kouadio D Koffi ${ }^{1}$, Zie \\ C Traore ${ }^{1}$, Mohamed Kouyate ${ }^{2}$
}

\begin{abstract}
Background: Breast cancer is a heterogeneous disease that represents a major public health problem. The immunohistochemical determination of breast cancer subtypes with regard to estrogen receptor (ER), progesterone receptor (PR), and human epidermal growth factor receptor (HER2) status can contribute to improved selection of therapy and patientcare. The purpose of this study was to determine the prevalence of the molecular breast cancer subtypes and to assess their associations with classical clinicopathologic parameters for better therapeutic decisions in women with breast cancer in the Ivory Coast. Materials and Methods: Formalinfixed and paraffin-embedded blocks of patients diagnosed with primary breast carcinoma were subjected to immunohistochemical assay for the assessment of ER/RP and HER2 expression. The one-way analysis of variance evaluated the difference between breast cancer subtypes and mean age of patients. The Chi-square Test was used to compare standard clinicopathologic prognostic parameters with tumor subtypes. Results. Among 302 patients, $57 \%$ were premenopausal and $43 \%$ were postmenopausal. The invasive ductal carcinoma not otherwise specified (IDC NOS) (82.8\%) was the most frequent histological type, and the tumor grade 2 (56\%) was predominant followed by grade $3(20.9 \%)$. The proportion of positivity of ER, PR, and HER2 was $56 \%$, $49 \%$, and $15.6 \%$, respectively. Half of patients of this study $(51.6 \%)$ had luminal A breast tumor type followed by TN (32.1\%). Other subtypes were luminal B $(10.1 \%)$ and non-luminal HER2+ $(6.3 \%)$. Conclusions. The findings of the present study are in line with the literature and should assist in management of breast cancer in our country.
\end{abstract}

Keywords: Breast cancer subtype - ER - PR - HER2 - Ivory Coast

Asian Pac J Cancer Prev, 17 (4), 1973-1978

\section{Introduction}

Breast cancer is the most common malignant tumor in women, and its mortality declines gradually due to advanced diagnostic and therapeutic methods in the developed countries. Nevertheless, this cancer-related mortality remains very high in the developing countries because of late diagnosis associated with a delay in treatment (Ferlay et al., 2013; Stewart and Wild, 2014). Breast cancer is a heterogeneous disease displaying clinical, pathological, and molecular varieties with various prognostic and therapeutic implications (Ronnov-Jessen et al., 1996; Perou et al., 2000; Sorlie et al., 2001; Geyer et al., 2009).

Recently, gene expression studies by microarrays of breast tumors have identified 5 subtypes, consisting of luminal A, luminal B, non-luminal HER2+, basal-like, and normal-like (Perou et al., 2000; Sorlie et al., 2001).
Genetic testing of breast cancer markers, such as estrogen receptor (ER), progesterone receptor (PR), and human epidermal growth factor receptor 2 (HER2) is not only very expensive but also exhibits technical difficulties. Therefore, the genomic classification cannot be applied in routine clinical practice. However, several studies have shown that the molecular classification based on gene expression of ER, PR, and HER2 is markedly correlated with immunohistochemical testing of these markers (Perou et al., 2000; Sorlie et al., 2001; Carey et al., 2006; Parise et al., 2009; Bauer et al., 2010; Paris and Caggiano, 2014). Despite the advanced genetic diagnostic methods, the management of breast cancer still depends on standard clinicopathologic prognostic factors associated with immunohistochemical (IHC) expression of ER/PR and HER2 (Geyer et al., 2009).

In Ivory Coast, breast cancer (34.2\%) represents the first cancer in women followed by cervical cancer (Ferlay 
et al., 2013). However, to the best of our knowledge, there are no data on the molecular breast cancer subtypes. Initially, the decision of hormone therapy was based on the breast cancer patients' menopausal status. Indeed, it was hypothesized that postmenopausal subjects would likely be expressed the ER/PR, and therefore, would benefit from systematic adjuvant tamoxifen, which remained ineffective without knowing the status of ER/PR and HER 2 of these patients. Since 2013, the routine ER/PR and HER2 immunohistochemical testing helps improve clinical, prognostic, and therapeutic outcomes in women with breast cancer in Ivory Coast. Thus, it appears urgent to carry out the present study to determine the prevalence of breast cancer molecular subtypes and their associations with the classical clinicopathologic parameters in the Ivorian patients.

\section{Materials and Methods}

\section{Patients}

The prospective study was conducted between November 2013 and June 2015, including 302 patients diagnosed with primitive and invasive breast carcinomas at the Central Laboratory in Abidjan, Ivory Coast. The histological diagnosis was performed upon formalinfixed and paraffin-embedded breast tissue blocks sampled from biopsies and mastectomies. On each sample, the histological type and the Nottingham grade of the tumor were determined according to the criteria of Elston and Ellis (Elston and Ellis, 1991). The parameters of the study were standard clinicopathologic prognostic parameters (age, menopausal status, histological type, and tumor grade) and the status of ER/PR and HER2. Formalinfixed and paraffin-embedded blocks of tissue breast were subjected to the IHC assay.

\section{Immunohistochemical analysis}

Formalin-fixed and paraffin-embedded specimens were cut into $3-\mu \mathrm{m}$ sections and mounted on positively charged slides. The slides were deparaffinized and heated in the drying oven

BINDER $^{\circledR}$ (BINDER Company, Tuttlingen, Germany) for at least 12 hours at $60^{\circ} \mathrm{C}$ to unmask the antigenic sites. The sections were stained using the Ventana Benchmark ${ }^{\circledR}$ GX in automatic mode (Ventana Medical Systems Inc., Tucson, AZ, USA) for the assessment of ER/PR and HER 2 expression. The antibody clones were monoclonal, developed in rats, consisted of SP1 for the ER, 1E2 for the PR, and 4B5 for the HER2, and manufactured by Ventana Medical Systems, Inc.

\section{ER/PR and HER2 staining assessment}

The visual analysis through the optic microscope allowed to quantify the percentage of tumor cells showing a nuclear immunostaining for ER and PR (range: 0-100\%). Breast tissue sections were considered positive for ER and PR if $\geq 1 \%$ of tumor cells showed a positive nuclear staining in accordance with the recommendations of the American Society of Clinical Oncology/ College of American Pathologists (Hammond et al., 2010). The HER2 scoring is based on the intensity of tumor cell membrane staining (on a scale of 0 to $3+$ ) and the percentage of positive tumor cells. Briefly, HER2 is negative for score 0 or $1+$, intermediate for score $2+$, and positive for score $3+$ (Wolff et al., 2013). The HER2 intermediate cases were not examined because the fluorescent in situ hybridization was not available in our laboratory. The percentages of ER/ $\mathrm{PR}$ and the score of HER2 were reviewed independently by two pathologists. In this study, the expression of Ki-67, cytokeratin 5/6 (CK 5/6) and human epidermal growth factor receptor 1 (HER1) were not examined. The triple negative consists of the basal-like type (ER-/PR-/ HER2-/ CK 5/6+ / HER1+) and normal-like type (all five markers are negative) (Nielsen et al., 2004). Herein, the breast cancer subtypes were defined according to the IHC expression of ER/PR and HER2 as follows (Carey et al., 2006; Parise et al., 2009; Bauer et al., 2010):

Luminal A (ER/PR+, HER2-) : ER+/PR+/HER2-; ER+/PR-/HER2-; ER-/PR+/HER2-

Luminal B (ER/PR+, HER2+): ER+/PR+/HER2+; ER+/PR-/HER2+; ER-/PR+/HER2+

Non luminal HER2+ (ER-/PR-/HER2+)

Triple negative (TN) (ER-/PR-/HER2-).

\section{Statistical analysis}

Data were collected in an Excel database from Windows 8 (Microsoft Corporation, Redmond, WA, USA). The difference between the breast cancer subtypes

Table 1. Clinicopathologic Characteristics in Breast Carcinoma Patients

\begin{tabular}{|c|c|}
\hline Variables & Number of patients $(\%)$ \\
\hline & $(\mathrm{N}=302)$ \\
\hline Mean age $( \pm \mathrm{SD})$ & $48 \pm 10.7$ \\
\hline \multicolumn{2}{|l|}{ Menopausal status } \\
\hline$<50$ years & $172(57)$ \\
\hline$\geq 50$ years & $130(43)$ \\
\hline \multicolumn{2}{|l|}{ Histologic type } \\
\hline IDC NOS & $250(82.8)$ \\
\hline Lobular & $13(4.3)$ \\
\hline Other & $39(12.9)$ \\
\hline \multicolumn{2}{|l|}{ Nottingham grade } \\
\hline 1 & $41(13.6)$ \\
\hline 2 & $169(56)$ \\
\hline 3 & $63(20.9)$ \\
\hline Undetermined* & $29(9.5)$ \\
\hline \multicolumn{2}{|l|}{ Estrogen receptor status } \\
\hline Positive & $169(56)$ \\
\hline Negative & $133(44)$ \\
\hline \multicolumn{2}{|c|}{ Progesterone receptor status } \\
\hline Positive & $148(49)$ \\
\hline Negative & $154(51)$ \\
\hline \multicolumn{2}{|l|}{ HER2 status } \\
\hline Negative & $241(79.8)$ \\
\hline Intermediate & $9(3)$ \\
\hline Positive & $47(15.6)$ \\
\hline Uninterpretable & $5(1.6)$ \\
\hline \multicolumn{2}{|l|}{ Molecular subtypes } \\
\hline Luminal A & 148 (51.6) \\
\hline Luminal B & $29(10.1)$ \\
\hline Non-luminal HER2+ & $18(6.3)$ \\
\hline Triple negative & $92(32.1)$ \\
\hline
\end{tabular}

Undetermined grade due to a very little breast tissue. SD: Standard deviation 
Table 2. Correlation of Clinicopathologic Parameters with Breast Cancer Subtypes

\begin{tabular}{|c|c|c|c|c|c|}
\hline Variables & $\begin{array}{c}\text { Luminal A } \\
(\mathrm{N}=148) \\
\mathrm{n}(\%)\end{array}$ & $\begin{array}{l}\text { Luminal B } \\
\qquad \begin{array}{c}\mathrm{N}=29) \\
\mathrm{n}(\%)\end{array}\end{array}$ & $\begin{array}{c}\text { Non- luminal HER2+ } \\
(\mathrm{N}=18) \\
\mathrm{n}(\%)\end{array}$ & $\begin{array}{l}\text { Triple negative } \\
\qquad \begin{array}{c}(\mathrm{N}=92) \\
\mathrm{n}(\%)\end{array}\end{array}$ & $\mathrm{p}$ value \\
\hline Age at diagnostic & & & & & 0.52 \\
\hline Mean $( \pm$ SD $)$ & $47.5 \pm 10.2$ & $48.8 \pm 11.2$ & $50.8 \pm 9.9$ & $48.7 \pm 11$ & \\
\hline Extreme & $24-83$ & $33-72$ & $27-84$ & $27-84$ & \\
\hline Menopausal status & & & & & 0.76 \\
\hline Premenopause & $85(57.4)$ & $17(58.6)$ & $8(44.4)$ & $52(56.5)$ & \\
\hline Postmenopause & $63(42.6)$ & $12(41.4)$ & $10(55.6)$ & $40(43.5)$ & \\
\hline Histologic type & & & & & 0.59 \\
\hline IDC NOS & $124(83.8)$ & $25(86.2)$ & $16(88.9)$ & $80(87)$ & \\
\hline Lobular & $9(6.1)$ & $3(10.3)$ & $0(0)$ & $3(3.3)$ & \\
\hline Other & $15(11.5)$ & $1(3.4)$ & $2(11.1)$ & $9(9.7)$ & \\
\hline Nottingham grade & & & & & $<0.00001$ \\
\hline 1 & 29 (19.6) & $1(3.4)$ & $0(0)$ & $9(9.8)$ & \\
\hline 2 & $86(58.1)$ & $21(72.4)$ & $15(83.3)$ & $40(43.5)$ & \\
\hline 3 & $18(12.2)$ & $6(20.7)$ & $2(11.1)$ & $34(37)$ & \\
\hline
\end{tabular}

SD: Standard deviation

defined by ER/PR and HER2 expression and the mean age were evaluated by the one-way analysis of variance. The Chi-Square Test was used to analyze associations of standard clinicopathologic prognostic parameters (menopausal status, histological type, and tumor grade) with breast tumor subtypes. A p-value $<0.05$ was considered statistically significant. The data were reported as frequencies for menopausal status, histological type, tumor grade, ER/PR status, and HER2 expression and as means for patients' age at diagnosis.

\section{Results}

\section{Characteristics of patients}

The mean age of all patients of this study was 48 \pm 10.7 years at the time of diagnosis (extremes: 24-84 years). The Table 1 shows clinicopathologic parameters in women with breast cancer. Among 302 patients, 57\% were premenopausal and $43 \%$ were postmenopausal. The invasive ductal carcinoma not otherwise specified (IDC NOS) $(82.8 \%)$ was the most frequent histological type, and the tumor grade $2(56 \%)$ was predominant followed by grade $3(20.9 \%)$. The proportion of positivity of ER, PR, and HER2 was 56\%, 49\%, and $15.6 \%$, respectively. Half of patients of this study $(51.6 \%)$ had luminal A breast tumor type followed by TN $(32.1 \%)$. Other subtypes were luminal B (10.1\% ) and non-luminal HER2+ $(6.3 \%)$.

\section{Association of standard clinicopathologic factors with} subtypes

The Table 2 summarizes the relationship between classical clinicopathologic features and molecular breast cancer subtypes. The mean age difference was not significantly associated with various tumor subtypes $(\mathrm{p}=0.52)$. The proportion of the molecular subtypes was linked to the menopausal status $(\mathrm{p}=0.76)$, although premenopausal patients displayed more luminal A and triple negative tumor types. The histological type was independent of the tumor molecular subtypes $(p=0.59)$.
Breast cancer categories defined by ER/PR and HER2 expression were closely correlated with the Nottingham grade $(\mathrm{p}<0.00001)$. The luminal A breast cancer patients had a relatively low grade with $19.6 \%$ of grade 1 and $58.1 \%$ of grade 2 compared to those of triple negative presenting high tumor grade with $43.5 \%$ of grade 2 and $37 \%$ of grade 3 .

\section{Discussion}

This manuscript represents the first study conducted in Ivory Coast, which determines the molecular groups of breast cancer based on the IHC expression of ER/PR and HER2 to guide the best therapeutic strategy for patients and to improve their survival.

In the present study, $56 \%$ of women with breast cancer expressed ER. This result is in accordance with the literature data (Adebamowo et al., 2008; Lin et al., 2009; Lowery et al., 2009; Ontilio et al., 2009; Joensuu et al., 2013; Inwald et al., 2013), but is higher than the finding reported in Ivory Coast (40\% in small sample size of 22 patients) (Coulibaly et al., 2008), in Ghana $(32,1 \%)$ (Seshie et al., 2015), in Nigeria/Senegal (24\%) (Huo et al., 2009). The high rate of ER positivity in our study confirms that the ER expression is undoubtedly the most significant biomarker in breast cancer. In fact, several studies have demonstrated that breast cancer is a hormone-related disease caused by the mitogenic effects of estrogen and progesterone (Knight et al., 1980; Weigel and Dowsett, 2010). Thus, the positivity of ER provides the index for sensitivity to hormone therapy (Byar et al., 1979; Weigel and Dowsett, 2010).

In our current study, the luminal A (51.6\%) was the most common breast cancer subtype, which was corroborated by results found in Europe (Lowery et al., 2009), in Asia (Lin et al., 2009), in Africa (Fouad et al., 2012; Tesfamariam and Roy, 2013), and in America (Carey et al., 2006; Ontilio et al., 2009; Kwan et al., 2009). In contrast, our finding is lower than data of some sub- 
Saharan African studies varying from $13.3 \%$ to $38 \%$ (Huo et al., 2009; Stark et al., 2010; Ly et al., 2012; Galukande et al., 2014; Seshie et al., 2015). Although the proportion of TN (32.1\%) in this study is similar to the findings of American black women (33.3\%) and Ugandan subjects (34\%) (Carey et al., 2006; Galukande et al., 2014), it is different from the rate found in Mali (46\%), in Nigeria/ Senegal (55\%), and in Ghana (82.2\%) (Huo et al., 2009; Stark et al., 2010; Ly et al., 2012). More importantly, our result remains high compared to Asian (Lin et al., 2009), North African (Fouad et al., 2012), white American (Carey et al., 2006; Kwan et al., 2009; Stark et al., 2010), and European populations (Lowery et al., 2009), where the TN represents $10-20 \%$ of breast cancer. $15.6 \%$ of our study population overexpressed HER2. This result is in agreement with the literature data which reported 10-30\% of HER 2 positive in invasive breast cancer, indicating that HER2 status remains steady in breast carcinoma (Gullick and Srinivasan, 1998; Beltjens et al., 2015).

The geographical variations of breast cancer subtypes proportions could be related to technical issues (Werner et al., 2000), environmental factors (Kwan et al., 2009 ; Trivers et al., 2009; Stark et al., 2010; Kurian et al., 2010), and genetic factors (Lakhani et al., 2002; Malone et al., 2006; Pal et al., 2015). More importantly, the significant rate of the $\mathrm{TN}$ in our study requires a particular attention and may result from a defect in preanalytical factors, particularly the duration and the quality of fixation, such as under fixation or prolonged fixation, and thus, causing the epitope loss, as investigated by Werner et al. (2000). Since the practice of IHC is recent in Ivory Coast, an effective collaboration among oncologists, radiologists, and pathologists is needed to improve the breast tissue fixation within recommended time for the therapeutic benefit of patients. Additionally, numerous studies have identified that breast cancer-related risk factors ,including poverty, multiparity, early age of first childbirth, short duration of breastfeeding, and black race are strongly associated with the elevated incidence of TN (Carey et al., 2006; Milikan et al., 2008; Kwan et al., 2009; Phipps et al., 2011; Ambrosone et al., 2014). The overrepresentation of TN among Ivorian women could be also illustrated by genetic factors. The predominance of this breast tumor type among the black American women is significantly associated with BRCA1 gene mutations that predispose them to develop this aggressive and resistant molecular subtype to hormone therapy (Lakhani et al., 2002; Malone et al., 2006; Pal et al., 2015). Lakhani et al. have found that breast cancer women associated with BRCA1 mutations are not more likely to express the ER, PR, and HER2 (Lakhani et al., 2002). The remarkable finding of Lakhani et al. underscores the need to conduct an in-depth study not only to assess the association of risk factors with triple negative patients but also to investigate the BRCA1 mutation status among triple negative women in Ivory Coast.

Molecular stratification of breast cancer has prognostic and therapeutic implications (Sorlie et al., 2001; Sorlie et al., 2003; Nielsen et al., 2004; Adebamowo et al., 2008; Blows et al., 2010). As a result, Luminal A patients have a more favorable prognosis and benefit from endocrine therapy; however, those of luminal B receive hormonotherapy along with chemotherapy (Sorlie et al., 2003; Blows et al., 2010). Unlikely, non-luminal HER2+ and TN subjects trastzumab and chemotherapy, respectively (Sorlie et al., 2001; Nielsen et al., 2004; Blows et al., 2010).

To determine the impact of standard clinicopathologic factors on the molecular breast cancer subtypes in this study, the relationship between these parameters and different tumor groups have been examined in 302 breast carcinomas. The mean age and the menopausal status were independent from molecular subtypes. This lack of correlation was found by several authors (Huo et al., 2009; Tesfamariam and Roy, 2013; Seshie et al., 2015) and could be clarified by the young age of our study population because of a relative short female life expectancy (54 years) in Ivory Coast. Before the advent of the IHC in Ivory Coast, adjuvant hormone therapy, tamoxifen, was systematic in postmenopausal women diagnosed with breast carcinoma. Nevertheless, our present study points out that the choice of tamoxifen should be given regardless the menopausal status for adequate medical care of patients in Ivory Coast. In addition, in our study, histological type was not related to various tumor subtypes, although they contain the majority of the IDC NOS. Our finding differs from result of Weigelt et al. (2008) and Huo et al. (2009). The absence of association of histologic type with cancer subtypes would probably be due to the sample size of our population study.

In this study, the tumor grading was closely correlated to the mammary subtypes. Interestingly, the TN patients displayed a relatively high grade compared to those of luminal groups. Our results are consistent with findings of other investigations (Carey et al., 2006; Huo et al., 2009; Lin et al., 2009; Ontilio et al., 2009; Paris and Caggiano, 2014), and thus, highlighting distinct clinical and therapeutic responses observed in breast cancer subtypes (Pusztai et al., 2003; Ontilio et al., 2009). The most common occurrence of TN in premenopausal women with high tumor grade may substantially explain the increased mortality rate due to breast cancer in the developing countries, particularly in Ivory Coast, where patients have limited access to ill-equipped health infrastructures. Our remarkable observations (high rate of TN in young women under 50 years exhibiting high tumor grade) corroborate with findings of other studies in the black American and the African women, confirming that the TN is strongly associated with unfavorable clinicopathologic prognostic parameters, and therefore, showing the aggressive feature of this subtype (Nielsen et al., 2004; Carey et al., 2006; Trivers et al., 2009).

Our study has some limitations. First, the unavailability of basal-like markers in our routine IHC testing did not allow us to distinguish the TN into basal-like and normallike categories. The differentiation of TN provides specific treatment strategies for normal-like type which has a favorable prognosis compared to basal-like group (Nielsen et al., 2004). Second, since the tumor size and the lymph node status were not considered in our study because of a large number of core needle biopsy breast samples, we were unable to evaluate the correlation of these significant 
clinicopathologic parameters with molecular breast cancer subtypes.

In conclusion, Breast cancer occurs in the young woman with high tumor grade. The most frequent molecular subtypes are the luminal $\mathrm{A}$ and the triple negative. The tumor grade of patients is significantly associated with tumor subtypes. The current study helps reevaluate the systematic use of hormone therapy and guide the therapeutic strategy choice for patients with breast carcinoma in Ivory Coast. The evaluation of basal-like markers (CK 5/6 and HER1) is recommended to distinguish triple negative for an effective therapy. Further studies should be carried out to investigate BRCA1 mutation status in triple negative breast cancer women in Ivory Coast.

\section{Acknowledgements}

This work was funded by the Roche - Hoffman and Novartis Laboratories - Ivory Coast. We thank the Roche-Hoffman Laboratory and the Ministry of Health for implementing the first Unit of Immunohistochemistry in Ivory Coast. We also thank the Central Laboratory in Abidjan, Ivory Coast for hosting this unit. We are grateful to Mr. Koffi Arthur and Ms. Gnenaho Pamela who performed the immunohistochemical technique.

\section{References}

Adebamowo CA, Famooto A, Ogundiran TO, et al (2008). Immunohistochemical and molecular subtypes of breast cancer in Nigeria. Breast Cancer Res Treat, 110, 183-8 .

Ambrosone CB, Zirpoli G, Ruszczyk M, et al (2014). Parity and breastfeeding among African-American women: differential effects on breast cancer risk by estrogen receptor status in the Women's Circle of Health Study. Cancer Causes Control, $\mathbf{2 5}, 259-65$

Byar DP, Sears ME, McGuire WL (1979). Relationship between estrogen receptor values and clinical data in predicting the response to endocrine therapy for patients with advanced breast cancer. Eur J Cancer, 15, 299-310.

Blows FM, Driver KE, Schmidt MK, et al (2010). Subtyping of breast cancer by immunohistochemistry to investigate a relationship between subtype and short and long term survival: a collaborative analysis of data for 10,159 cases from 12 studies. PLoS Med, 7, 1000279.

Bauer K, Parise C, Caggiano V (2010). Use of ER/PR/HER2 subtypes in conjunction with the $2007 \mathrm{St}$ Gallen Consensus Statement for early breast cancer. BMC Cancer, 10, 228.

Beltjens F, Bertaut A, Pigeonnat S, et al (2015). HER2positivity rates in breast cancer: no variation over time when clinicopathological features and testing are stable. Eur $J$ Cancer Care, DETAILS?

Carey LA, Perou CM, Livasy CA, et al (2006). Race, breast cancer subtypes, and survival in the carolina breast cancer study. JAMA, 295, 2492-502.

Coulibaly JD, Effi AB, Horo GA, et al (2008). Hormonal status and overexpression of HER2 in breast cancer, Cancerology department of Treichville UHC. Preliminary results. Bull Cancer, 95, 799-803.

Elston CW, Ellis IO (1991). Pathological prognostic factors in breast cancer. I. The value of histological grade in breast cancer: experience from a large study with long-term followup. Histopathol, 19, 403-10.
Fouad A, Yousra A, Kaoutar Z, et al (2012). Molecular Classification of breast cancer in Morocco. Pan Afr Med $J, 13,9$.

Ferlay J, Soerjomataram I, Ervik M, et al (2013). GLOBOCAN 2012 v1.0, Cancer Incidence and Mortality Worldwide: IARC Cancer Base No. 11 [Internet]. Lyon, France: International Agency for Research on Cancer. Available from: http://globocan.iarc.fr. Assessed 25 Oct 2015.

Gullick WJ, Srinivasan R (1998). The type 1 growth factor receptor family: new ligands and receptors and their role in breast cancer. Breast Cancer Res Treat, 52, 43-53.

Geyer FC, Lopez-Garcia MA, Lambros MB, Reis-Filho JS (2009). Genetic characterization of breast cancer and implications for clinical management. J Cell Mol Med, 13, 4090-103.

Galukande M, Wabinga H, Mirembe F, Karamagi C, Asea A (2014). Molecular breast cancer subtypes prevalence in an indigenous Sub-Saharan African population. Pan Afr Med $J, \mathbf{1 7}, 249$.

Huo D, Ikpatt F, Khramtsov A, et al (2009). Population Differences in Breast Cancer: Survey in Indigenous African Women Reveals Over-Representation of Triple-Negative Breast Cancer. J Clin Oncol, 27, 4515-2.

Hammond ME, Hayes DF, Dowsett M, et al (2010). American society of clinical oncology/college of american pathologists guideline recommendations for immunohistochemical testing of estrogen and progesterone receptors in breast cancer. Arch Pathol Lab Med, 134, 907-22.

Knight WA 3rd, Osborne CK, McGuire WL (1980). Hormone receptors in primary and advanced breast cancer. Clin Endocrinol Metab, 9, 361-8.

Inwald EC, Klinkhammer-Schalke M, Hofstädter F, et al (2013). Ki-67 is a prognostic parameter in breast cancer patients: results of a large population-based cohort of a cancer registry. Breast Cancer Res Treat, 139, 539-52.

Joensuu K, Leidenius M, Kero M, et al (2013). ER, PR, HER2, Ki-67 and CK5 in early and late relapsing breast cancerreduced CK5 expression in metastases. Breast Cancer, 7, 23-34.

Kurian AW, Fish K, Shema SJ, Clarke CA (2010). Lifetime risks of specific breast cancer subtypes among women in four racial/ethnic groups. Breast Cancer Res, 12, 99.

Lakhani SR, Van De Vijver MJ, Jacquemier J, et al (2002). The pathology of familial breast cancer: predictive value of immunohistochemical markers estrogen receptor, progesterone receptor, HER-2, and p53 in patients with mutations in BRCA1 and BRCA2. J Clin Oncol, 20, 23102318.

Lowery AJ, Miller N, Devaney A, et al (2009). MicroRNA signatures predict oestrogen receptor, progesterone receptor and HER2/neu receptor status in breast cancer. Breast Cancer Res, 11, 27.

Lin CH, Liau JY, Lu YS, et al (2009). Molecular subtypes of breast cancer emerging in young women in Taiwan: evidence for more than just westernization as a reason for the disease in Asia. Cancer Epidemiol Biomarkers Prev, 18, 1807-14.

Ly M, Antoine M, Dembélé AK, et al (2012). High incidence of triple-negative tumors in Sub-Saharan Africa: a prospective study of breast cancer characteristics and risk factors in Malian women seen in a Bamako university hospital. Oncol 83, 257-63.

Kwan ML, Kushi LH, Weltzien E, et al (2009). Epidemiology of breast cancer subtypes in two prospective cohort studies of breast cancer survivors. Breast Cancer Res, 11, 31 .

Malone KE, Daling JR, Doody DR, et al (2006). Prevalence and predictors of BRCA1 and BRCA2 mutations in a population based study of breast cancer in White and Black American 
Ahoua B Effi et al women ages 35 to 64 years. Cancer Res, 66, 8297-308.

Millikan RC, Newman B, Tse C-K, et al (2008). Epidemiology of basal-like breast cancer. Breast Cancer Res Treat, 109, 123-39.

Nielsen TO, Hsu FD, Jensen K, et al (2004). Immunohistochemical and clinical characterization of the basal-like subtype of invasive breast carcinoma. Clin Cancer Res, 10, 5367-74.

Onitilo AA, Engel JM, Greenlee RT, Mukesh BN (2009). Breast cancer subtypes based on ER/PR and Her2 expression: comparison of clinicopathologic features and survival. Clin Med Res, 7, 4-13.

Perou CM, Sørlie T, Eisen MB, et al (2000). Molecular portraits of human breast tumours. Nature, 406, 747-52.

Pusztai L, Ayers M, Stec J, et al (2003). Gene expression profiles obtained from fine-needle aspirations of breast cancer reliably identify routine prognostic markers and reveal large-scale molecular differences between estrogen-negative and estrogen-positive tumors. Clin Cancer Res, 9, 2406-15.

Parise CA, Bauer KR, Brown MM, Caggiano V (2009). Breast cancer subtypes as defined by the estrogen receptor (ER), progesterone receptor (PR), and the human epidermal growth factor receptor 2 (HER2) among women with invasive breast cancer in California, 1999-2004. Breast J, 15, 593-602.

Phipps AI, Chlebowski RT, Prentice R, et al (2011). Reproductive history and oral contraceptive use in relation to risk of triplenegative breast cancer. J Natl Cancer Inst, 103, 470-7.

Parise CA, Caggiano V (2014). Breast cancer survival defined by the ER/PR/HER2 subtypes and a surrogate classification according to tumor grade and immunohistochemical biomarkers. J Cancer Epidemiol.

Pal T, Bonner D, Cragun D, et al (2015). A high frequency of BRCA mutations in young black women with breast cancer residing in Florida. Cancer, 121, 4173-80.

Rønnov-Jessen L, Petersen OW, Bissell MJ (1996). Cellular changes involved in conversion of normal to malignant breast: importance of the stromal reaction. Physiol Rev, 76, 69-125.

Sørlie T, Perou CM, Tibshirani R, et al (2001). Gene expression patterns of breast carcinomas distinguish tumor subclasses with clinical implications. Proc Natl Acad Sci USA, 98, 10869-74.

Sorlie T, Tibshirani R, Parker J, et al (2003). Repeated observation of breast tumor subtypes in independent gene expression data sets. Proc Natl Acad Sci U S A, 100, 8418-23.

Stark A, Kleer CG, Martin I, et al (2010). African ancestry and higher prevalence of triple-negative breast cancer: findings from an international study. Cancer, 16, 4926-32.

Stewart WB, Wild PC (2014). World cancer report. $3^{\text {rd }}$ ed. Lyon: IARC.

Seshie B, Adu-Aryee NA, Dedey F, et al (2015). A retrospective analysis of breast cancer subtype based on ER/PR and HER2 status in Ghanaian patients at the Korle Bu Teaching Hospital, Ghana. BMC Clin Pathol, 15, 14.

Trivers KF, Lund MJ, Porter PL, et al (2009). The epidemiology of triple-negative breast cancer, including race. CCC, $\mathbf{2 0}$, 1071-82.

Tesfamariam A, Roy I (2013). Molecular biology of breast cancer in the horn of africa: case series-a pilot study of breast cancer from eritrea. ISRN Pathol.

Werner M, Chott A, Fabiano A, Battifora H (2000). Effect of formalin tissue fixation and processing on immunohistochemistry. Am J Surg Pathol, 24, 1016-9.

Weigelt B, Horlings HM, Kreike B, et al (2008). Refinement of breast cancer classification by molecular characterization of histological special types. J Pathol, 216, 141-50.

Weigel MT, Dowsett M (2010). Current and emerging biomarkers in breast cancer: prognosis and prediction.
Endocr Relat Cancer, 17, 245-62.

Wolff AC, Hammond ME, Hicks DG, et al (2013). American society of clinical oncology/college of american pathologists. recommendations for human epidermal growth factor receptor 2 testing in breast cancer: American Society of Clinical Oncology/College of American Pathologists clinical practice guideline update. J Clin Oncol, 31, 3997-4013. 